\title{
Some Recent Developments at NBS in Mass Measurements
}

\author{
RANDALL M. SCHOONOVER AND JAMES E. TAYLOR
}

\begin{abstract}
During the early 1970 's the results of a routine circulation of some mass artifacts between several laboratories revealed unexpected systematic errors. Our interest in understanding these anomalies led us to undertake several projects that are soon to be incorporated into a new round-robin effort. We believe this new work will demonstrate that the mass unit can be disseminated through artifacts of less than ideal characteristics and the results remain free of serious systematic errors. Such a demonstration will not only increase our confidence in the calibration of mass strandards but should also point to areas where fine tuning can yield further improvements on a laboratory-by-laboratory hasis.

We will discuss the effects on mass measurement of artifact characteristics, i.e., geometry, thermal conductivity, density, etc. The role played by the interaction of these artifact properties with ambient conditions is important to the outcome of a mass measurement process. To minimize these interactions we have applied electronic control circuitry to the weighing process. Our next round-robin weight package uill contain the developments which are discussed in this paper.
\end{abstract}

\section{BACKGROUND}

$\mathrm{I}$ N 1964, in preparation for the development of a silicon density standard. we performed an experiment to test the correctness of the air density equation [1] used in making buoyancy corrections when comparing masses of differing density. The method was the usual one of using an air density formula that provides a calculation based on the measured parameters of air temperature, barometric pressure. and relative humidity [2]. The first part of the experiment was the determination of the volume difference $\Delta V$ and of the mass difference $\Delta M$. in vacuum, of two artifacts with large differences in their densities $\left(7.8\right.$ and $\left.1.0 \mathrm{~g} / \mathrm{cm}^{3}\right)$. A subsequent weighing of the objects in air resulted in a direct determination of air density $\rho$, where $\rho=\Delta M / \Delta V$. The measured air density was then compared to values calculated based on the above-mentioned parameters. These data are summarized in Table I. The calculated air density minus the gravimetrically determined air density is given as $\Delta \rho$. In the intervening years other experimenters have substantiated these results. Our conclusion was that $\Delta \rho$ was sufficiently small and air density equations were adequate for making buoyancy corrections in mass measurements. It was therefore disturbing to the metrological community when other data suggested that a serious inadequacy existed. The reported

Manuscript received March 25, 1986.

The authors are with the National Bureau of Standards, Gaithersburg. MD 20899.

IEEE Log Number 8610873.
TABLE I

ThF Difference in Air DeNsity $\Delta \rho$ Calclilated by Slbtracting the Gravimetrically Determined Valle from That Calclilated Using AMBIENT PARAMETERS

\begin{tabular}{|c|c|c|c|c|c|c|}
\hline TEST & $\begin{array}{c}\text { NUMBER } \\
\text { OF } \\
\text { OBSER. } \\
\text { VATIONS }\end{array}$ & $\begin{array}{c}\text { RANGE IN } \\
\text { RELATIVE } \\
\text { HUMIDITY } \\
1{ }^{\circ} \mathrm{cl}\end{array}$ & $\begin{array}{l}\text { RANGE } \\
\text { IN } \\
\text { PRESS } \\
\text { imm Hg) }\end{array}$ & $\begin{array}{l}\text { RANGE } \\
\text { IN } \\
\text { TEMP } \\
1^{\circ} C_{1}\end{array}$ & $\begin{array}{c}A V G \\
\Delta P \\
(\mu \mathrm{g} / \mathrm{Cm})\end{array}$ & $\begin{array}{l}\text { STD DEV } \\
\text { IN } \Delta \rho \\
\text { (mgicm) }\end{array}$ \\
\hline FIRST & 29 & $\begin{array}{r}173 \\
409 \\
\end{array}$ & $\begin{array}{r}742.3 \\
7563 \\
\end{array}$ & $\begin{array}{r}240 \\
270 \\
\end{array}$ & -014 & 0.49 \\
\hline SECOND & 42 & $\begin{array}{r}73 \\
36.3\end{array}$ & $\begin{array}{l}7460 \\
7694\end{array}$ & $\begin{array}{l}215 \\
267\end{array}$ & +0.35 & 0.39 \\
\hline
\end{tabular}

data [3] indicated that the buoyancy correction had a noticeable dependence on barometric pressure, the implication being that there existed systematic errors in mass values assigned by laboratories at differing altitudes when the artifacts have large differences in displacement volumes.

In our efforts to find some experimental failure that would cause such anomalous results, we carefully examined the various instruments and artifacts used in the measurement and found the integrity of them all to be intact. Surface effects were considered to the extent that we examined the aluminum kilogram used in the work for variations in mass related to changes in relative humidity. These data are presented in Fig. 1 and reveal no such correlation at the level of the measurement precision.

\section{New High-Altitude Measurements}

In 1979. with the cooperation of Sandia Laboratories, new measurements [4] near sea level (Washington, DC) and at $1600 \mathrm{~m}$ (Albuquerque. New Mexico) were undertaken. In addition to the tantalum and aluminum kilograms, several other artifacts which had been especially prepared for vacuum weighing were included. Great care was taken to insure the integrity of these measurements. including the use of a recent air density formulation and error analysis [2].

All of the mass values given in both Figs. 2 and 3 were derived by comparison to a $1-\mathrm{kg}$ stainless-steel mass standard. The stainless-steel kilogram is nearly equal to the mass standard in density and shows a random scatter which is consistent with that observed in a single laboratory. This finding is also true for the aluminum and tantalum weighing results, that is, no extraordinary behavior was observed and the assigned values are within the predicied limits reported in [4]. However, the reader should 


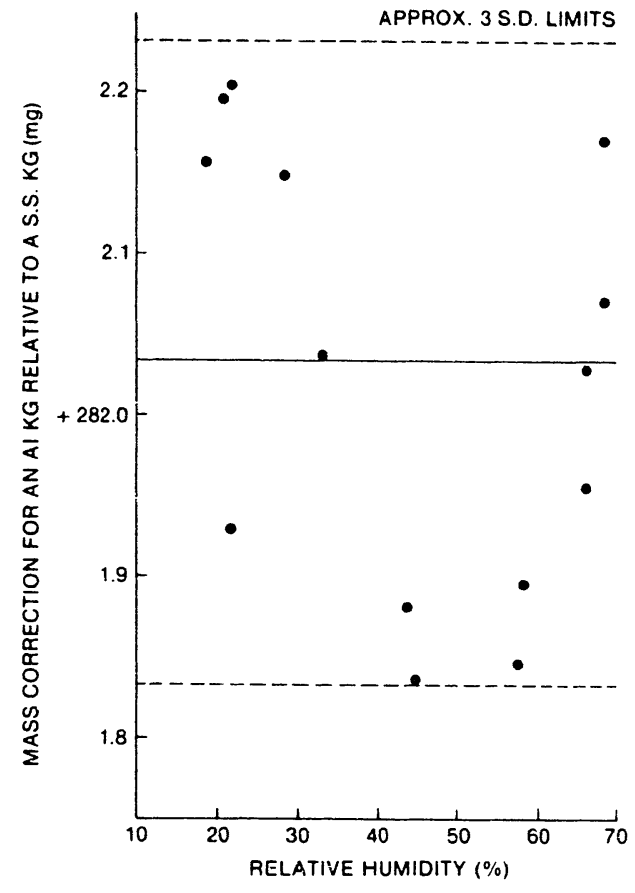

Fig. 1. The mass correction assigned to an aluminum kilogram by comparison to a stainless-steel kilogram at various relative humidities.

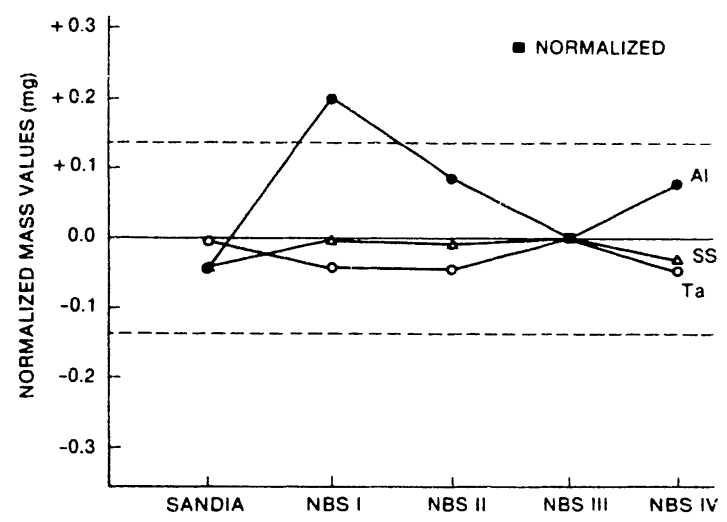

Fig. 2. Mass values to three 1-kg weights obtained by comparison to a stainless-steel $\mathrm{kg}$ mass standard. (Each of the kilograms is of a different material: tantalum ( $\mathrm{Ta}$ ), aluminum ( $\mathrm{Al})$, and stainless steel (SS). These assignments were made at two locations differing by $1600 \mathrm{~m}$ in altitude. It is significant that the aluminum kilogram values lie above the stainlesssteel kilogram while the tantalum kilogram values for the most part are below the stainless steel.)

note that the data for the aluminum and tantalum kilograms have been normalized to the stainless-steel kilogram value of NBS III. The aluminum and tantalum mass values are the mean of four measurements of each kilogram. Thus the data of Figs. 2 and 3 (the anomalous data) are easily compared. The 99-percent confidence limits indicated by the dotted lines in Figs. 2 and 3 are those applied to a normal calibration procedure used during the early 1970's and are based on statistical data for hundreds of similar measurements of weights with densities in the range of $7.8-8.4 \mathrm{~g} / \mathrm{cm}^{2}$.

Although the data of Fig. 2 lie within the estimated un-

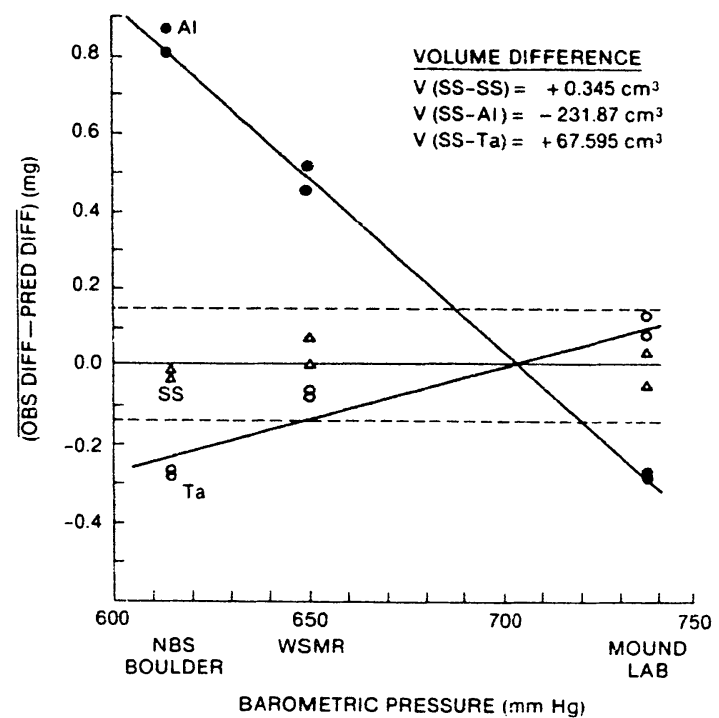

Fig. 3. The anomalous data taken at various altitudes from near sea level to $1600 \mathrm{~m}$. (The tantalum and aluminum kilograms are the same ones referred to in Fig. 2.)

certainty, systematic differences are present, that is, the aluminum kilogram mass values either coincide with the stainless-steel kilogram or lie above it. Likewise most of the tantalum kilogram values either concide with or lie below the stainless-steel kilogram. We refer to this systematic behavior as "clustering." It is the distinct clustering of the values of the first three measurements that led to the last two additional NBS measurements. The observers noted that the Sandia measurement was conducted in a thermally controlled laboratory at $20^{\circ} \mathrm{C}$ and the NBS I and NBS II were measurements not thermally controlled and near $23^{\circ} \mathrm{C}$. The clustering of these data was believed to be related to a lack of thermal equilibrium between the masses and the surrounding air or some other surface effect. The NBS III measurement was conducted in a room thermally controlled at $21^{\circ} \mathrm{C}$, near the Sandia condition. Likewise, the NBS IV measurement was controlled at $23^{\circ} \mathrm{C}$ near the other NBS measurement temperatures.

We note that the NBS III and Sandia results agree well with each other as do the other measurements, all within predicted limits. However, when all of the measurements are viewed together, the clustering is noticeable. Furthermore, we note that controlling the thermal environment provides a stable thermal history before the measurement begins; however, the operator's body heat causes an almost immediate and observable temperature offset between the artifact and the surrounding air. In an uncontrolled environment the temperature offset changes continually in an unknown manner, as our later work revealed.

\section{Additional Studies}

In more recent work, two additional studies were undertaken to further understand problems associated with the interaction of surface-to-mass ratios and the lack of thermal equilibrium. These two studies were conducted 
simultaneously. It is more enlightening to examine first the study [5] which was designed to look for these effects at NBS, excluding significant buoyancy corrections like those encountered in weighing the aluminum kilogram. Having examined these results, we can then consider the seconu siuciy [ó], designed to detect the very same effects in the world beyond NBS and, in addition, examine the problems associated with the buoyancy correction in many different laboratories. This study, a "round-robin" involving seven laboratories, utilizes the special $1-\mathrm{kg}$ artifacts mentioned earlier but not yet discussed. With the results of this study, we can return to the problem of the anomalous data with a better understanding, and consider new approaches to solving the problem.

After the measurements were completed at NBS and Sandia Laboratories we designed a simple experiment to explore the "clustering data problem" without introducing buoyancy correction. A chemist. Ellis Blade, reported in 1946 on weighing errors encountered when weighing "hot" crucibles and plummets [7]. A weighing experiment was designed to examine the measured differences between $10-\mathrm{g}$ stainless-steel mass standards and several $10-\mathrm{g}$ sheet metal weights made from stainless steel and copper.

The 10-g stainless-steel mass standards are designed to have a height equal to their diameter, thereby minimizing their surface-to-mass ratio. On the other hand the sheet metal weights had massive surface areas in comparison and the copper weights have different thermal conductivity, surface finish, and emissivity than the others. Table II briefly summarizes some of the characteristics. For brevity we have not shown the copper weight data.

The experimental weighing design allowed two stainless-steel standard weights to always remain inside a suitable balance. Stored outside the balance on a temperaturecontrolled block (soaking plate) were two identical weights and two sets of sheet metal weights of both stainless steel and copper. The soaking plate was placed alongside the balance and the weights were allowed to reach thermal equilibrium with the plate before weighing began. The weighing design provided for comparison of the standard weights. inside the balance, to each other and to the others at various temperatures above and below that of the balance. The design also provided for the sheet metal weights to be compared in different orientations on the balance weighing pan. Furthermore, on occasion all the weights were allowed to come to thermal equilibrium inside the balance before they were compared.

During the experiment, 79 measurements were made between the two standards stored inside the balance and a constant difference $(A-B)$ was observed for these weights (see Table III, row 1). This difference was constant to within a standard deviation of $8.6 \mu \mathrm{g}$. A similar standard deviation was found for the two identical weights that remained outside the balance at equal temperature, but which differed from the balance temperature by as much as $\pm 4^{\circ} \mathrm{C}$ (see Table 11I, row 2). When masses $A$ and $B$ were compared after storage at different temperatures, row
TABLE II

A Summary of the Pertinent Characteristics of the 10-g Weights Used to Examine Surface-Dependent Thermal EfFEcts

\begin{tabular}{|c|c|c|}
\hline $\begin{array}{c}\text { PHYSICAL } \\
\text { CHARACTERISTICS }\end{array}$ & $\begin{array}{l}\text { WEIGHTS } \\
\text { A AND B }\end{array}$ & $\begin{array}{l}\text { WEIGHTS } \\
\text { C AND D }\end{array}$ \\
\hline $\begin{array}{l}\text { MASS } \\
(g !\end{array}$ & 10 & 10 \\
\hline GEOMETRY & $\begin{array}{l}\text { CYLINDRICAL } \\
(H G H T=D \mid A)\end{array}$ & $\begin{array}{c}\text { FLAT SHEET } \\
\text { METAL }\end{array}$ \\
\hline MATERIAL & $\begin{array}{l}\text { STAINLESS } \\
\text { STEEL }\end{array}$ & $\begin{array}{l}\text { STAINLESS } \\
\text { STEEL }\end{array}$ \\
\hline $\begin{array}{l}\text { DENSITY } \\
\left(\frac{9}{\mathrm{~cm}^{3}}\right)\end{array}$ & 7.89 & 7.80 \\
\hline $\begin{array}{l}\text { SURFACE AREA } \\
\text { (C: } ?: ?\end{array}$ & 6 & $4 ?$ \\
\hline $\begin{array}{l}\text { SURFACE TO MASS RATIO } \\
\qquad\left(\frac{\mathrm{cm}}{\mathrm{g}}\right)\end{array}$ & 0.6 & 4.3 \\
\hline $\begin{array}{l}\text { DIMENSIONS } \\
\text { (cm) }\end{array}$ & $\begin{array}{l}\text { HEIGHT }=1.05 \\
\text { DIAMETER }=1.23\end{array}$ & $\begin{array}{l}\text { HEIGHT }=\quad 8.30 \\
\text { WIDTH }=2.54 \\
\text { THICKNESS }=0.06\end{array}$ \\
\hline
\end{tabular}

3 of Table III shows that the observed mass difference depended strongly on the temperature difference. This difference approaches the true mass difference as the temperature difference between the masses approaches zero.

The sheet metal weights at the conditions give in Table III, row 4 exhibited the same behavior as the weights of row 2 but with a serious loss in measurement precision. The measurement between the standard and the sheet metal weights at differing temperatures is illustrated by row 5 in Table III. Not only is the measure difference dependent on the temperature but also orientation of the weight on the balance pan. It is most interesting that when the weight temperature is near equilibrium with the balance (less than $0.1^{\circ} \mathrm{C}$ ) the slope becomes very steep indicating extreme sensitivity to the temperature difference. The stainless-steel and copper sheet metal weights demonstrated about the same effect for all measurements indicating that surface finish, thermal conductivity, and emissivity do not play an important role.

The second study, a round-robin between seven laboratories including NBS, used an ordinary stainless-steel kilogram and the special stainless-steel kilograms mentioned earlier. The pertinent characteristics, surface areas, and height ratios relative to the standard are given in $\mathrm{Ta}$ ble IV. The values shown for each laboratory and the corresponding artifacts are the difference between the average NBS value and the value assigned by the respective laboratory. When we examine the data (except for weight $H 2$ ), we can see the range in assigned mass values correlates not with surface area but rather with height relative to the standard, where the standard charactersitics are similar to those of weight $A 1$.

Thus from these experiments we can conclude that there are drag forces that result when the air surrounding the weight is set into motion by unequal temperatures between the weight and the air. It has been shown in Table III that the direction of the drag force either adds to or 
TABLE III

Summaries of the Measured Mass Difference Between Two Weights WITH TEMPERATURE HISTORIES BY ROWS

Standard deviations are not applicable and not given for rows 3 and 5 .

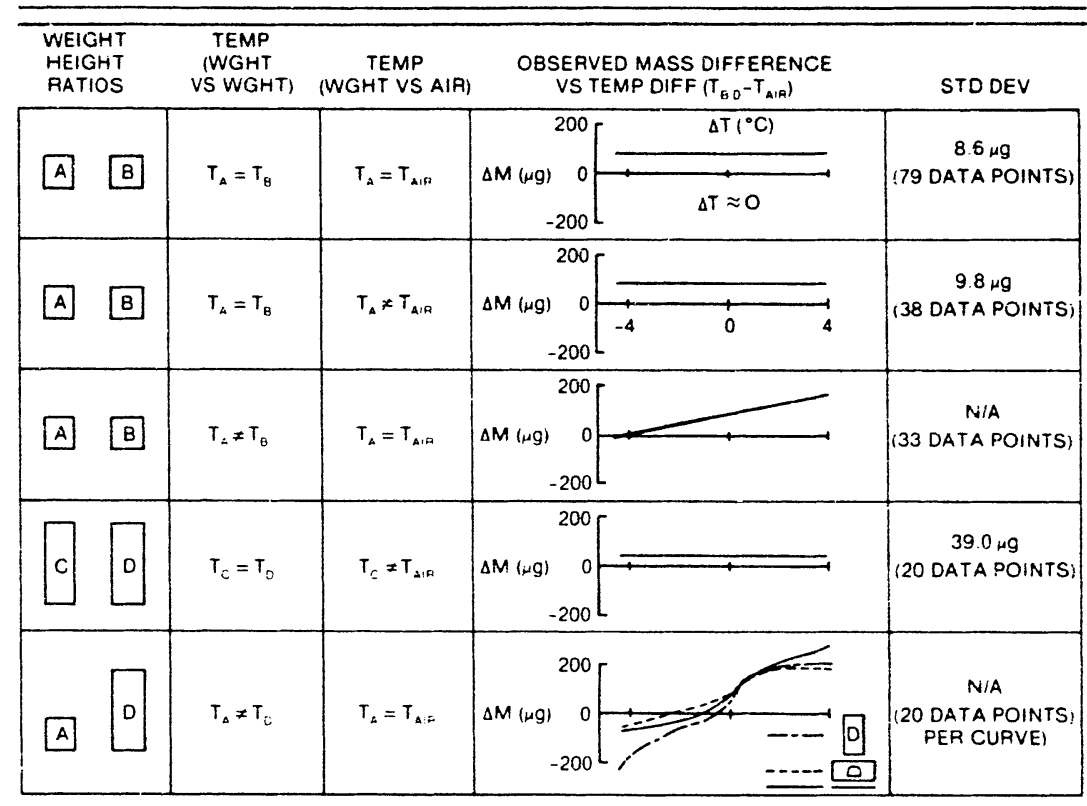

TABLE IV

The Results of a Round-Robin Between NBS and Six Other LABORATORIES

The range in values assigned to kilograms $A 1, S 2$, and $R 2$ correlate with the height ratio to a standard identical to $A 1$.

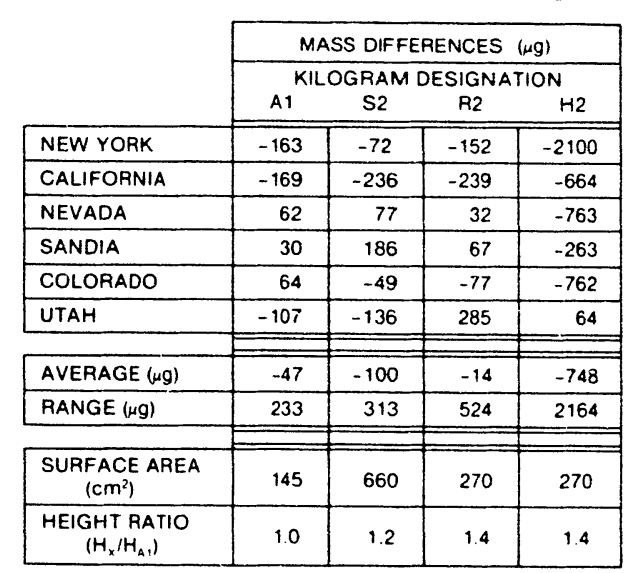

subtracts from the gravitational force imposed on the balance. The direction depends on whether the mass is varmer or colder than the surrounding air and the magnitude of the force is related to the temperature difference between the mass and the air. In addition, Table IV illustrates variations in the range of mass values. These variations correlate well with the height ratios among the artifacts.

A hollow stainless steel weight $\boldsymbol{H} 2$ with a density of $2.7 \mathrm{~g} / \mathrm{cm}^{3}$ was included in the seven-laboratory round-robin package in order to obtain data on the buoyancy correction itself. The range of data in Table IV for weight
$H 2$ shows that there remains a serious problem that is directly attributable to many of the participating laboratories not being able to measure the parameters for calculating air density. The least accurate measurement was found to be barometric pressure.

\section{The Next Round-Robin}

It is apparent from the various measurements we have discussed that a round-robin mass measurement containing artifacts of unusual geometry or density has several pitfalls. Those discussed thus far are the most serious problems encountered, but not the only ones. Some others were the details of the data reduction algorithm and the lack of adequate instrumentation, except for the balances themselves. A final problem is that round-robins place a disproportionate share of the work load on NBS staff. To insure the beneinis of future round-robins to all interested participants, this last difficulty must be overcome.

We iterate our difficulties here once again:

1) surface-dependent effects related to the lack of thermal equilibrium;

2) inadequate measurement of air temperature, barometric pressure, and relative humidity:

3) lack of uniform data reduction; and

4) work load.

We believe the solutions we have developed in response to these problems will make the next round-robin nearly free of these difficulties.

First and foremost to ensure future success, the thermal problems must be solved in a practical way that can work 
in most existing laboratories. Of course, every laboratory would like a better environmental control system but usually this is merely "shooting for the moon." However, we have improved the thermal conditions of the weights and the weighing chamber, prior to weighing, in the following ways. First, placed beside the balance is an aluminum soaking plate for the masses undergoing calibration to be stored. This plate and the balance weighing chamber both contain a $100-\Omega$ platinum resistance thermometer. These thermometers are part of a bridge and control circuit [8] that force the weights and air inside the weighing chamber into thermal equilibrium. The longterm (days) temperature differences are less than $0.01^{\circ} \mathrm{C}$. Second, to prevent the operator from disturbing this equilibrium condition with his presence, a body-heat simulator is placed in front of the balance. This simulator is a nichrome heating element radiating in the infrared region and is removed by the operator when the weighing operation begins.

Our thermal studies [5] included looking at the lag times for various masses to achieve thermal equilibrium with the balance. We found weights equilibrate according to the equation

$$
T_{l}-T_{R}=A e^{-\left(t / B_{M}\right)}
$$

where $T_{l}$ is the initial weight temperature, $T_{R}$ is the balance temperature, $t$ is time, $A$ is equivalent to the initial temperature difference, and $B_{M}$ is a combination of several physical constants determined for the artifact experimentally. Furthermore, an operator's presence causes an immediate temperature rise inside the balance of approximately $0.2^{\circ} \mathrm{C}$, which a $1-\mathrm{kg}$ stainless-steel mass standard cannot immediately follow. The calculations shows that about $7 \mathrm{~h}$ are required to reach within $0.01^{\circ} \mathrm{C}$ of equilibrium when the offset is $1^{\circ} \mathrm{C}$.

From experience, we have learned to design a weight with greater sensitivity to thermal effects. One makes its height much greater relative to the standard weight. This we have done in preparation for the next round-robin. The $1-\mathrm{kg}$ weight that will be used is approximately $2.5 \mathrm{~cm}$ in diam, $19 \mathrm{~cm}$ long, and has a density of $8.0 \mathrm{~g} / \mathrm{cm}^{3}$. The results obtained using this weight should be a good indicator of how well our preventive actions are working in each laboratory.

The remaining problems are easily solved with nearly total automation of the package. The package includes a personal computer with data reduction and control software interfaced via an IEEE488 bus multiplexed to a voltmeter that reads a thermistor thermometer, a capacitance humidity indicator, and a capacitance aneroid barometer.
Thus not only will the work load on NBS be reduced but also for the participating laboratories. In addition, the software package is designed to aid the operator and thereby assure uniformity in both the measurement process and data reduction.

The balance operator must enter the balance observations from the computer keyboard. This operation has been eliminated at NBS by our development of a balance beam servo-control that has been retrofitted to several balances. The balance servo in itself is of interest and will be reported separately in the near feature. One important feature of the balance servo-control is that its electronic nature enables automatic data acquisition of the balance observations. Since commercial balances of equal range with electronic readout generally lack adequate precision, other laboratories may wish to modify their mechanical balances in the same way. For a time we had achieved total automation with the addition of an automatic weight exchanger to our balance. Although the results were very good, it was impractical, and is no longer in use.

\section{The Future}

We believe the studies just described have enabled us to design a comprehensive round-robin package that will eliminate most significant anomalies, and the results of our next effort should yield consistent results from all of the participating laboratories. It is also expected that the potential application of the on-site self-teaching aspects of this package will be fully explored. We also hope, eventually, to expand the software so that participants can perform an NBS-traceable calibration on their laboratory standards, in situ, from $1 \mathrm{~kg}$ to $1 \mathrm{mg}$.

\section{REFERENCES}

[1] H. A. Bowmar R. M. Schoonover, "Procedure for high precision density determınation by hydrostatic weighing, 'J. Res., vol. 71C, pp. 179-198, July-Aug. 1967.

[2] F. E. Jones, "The air density equation and the transfer of the mass unit,"J. Res., vol. 10, pp. 419-427. Sept.-Oct. 1978.

[3] P. E. Pontius, "Mass measurement: A study of anomalies," Science, vol. 190, pp. 379-380, 1975.

[4] R M. Schoonover, R. S. Davis, R. G. Driver, and V. E. Bower, “A practical test of the air density equation in standards laboratories at differing altitudes," J. Res., vol. 85, no. 1, pp. 27-38, Jan.-Feb. 1980.

[5] R. M. Schoonover and J. Keller, "A surface-dependent thermal effect in mass calibration," in "Report of the 68th National Conference on Weights and Measures 1983." NRS S. erial Put. 653, pp. 39-57, 1983.

[6] R. M. Schoonover, "Advanced mass calibration in stats laboratories," Rep. NBSIR 83-2752, pp. 1-9, Aug. 1983.

17] E. Blade, "Differential temperature error in weighing," Ind. Eng. Chem., ed. 12, p. 330, 1943.

[8] R. D. Cutkosky and R. S. Davis, "Simple control circuit for temperature regulation and other bridge applications," Rev. Sci. Instrum. vol. 52, no. 9, pp. 1403-1405, Sept. 1981. 